\title{
Italian translation and validation of the GQ-6
}

\author{
Andrea Caputo
}

\begin{abstract}
This paper aims at translating the Gratitude Questionnaire (GQ-6) into Italian and at investigating its validity and reliability in this context. In a web-based survey, 204 adult participants $(M$ age $=28.96 ; S D=10.27)$ completed the Italian version of the GQ-6, as well as subjective happiness, life satisfaction, loneliness, and social desirability questionnaires. Exploratory and confirmatory factor analyses supported a one-factor solution explaining $46.16 \%$ of the variance of the original items and an acceptable Cronbach's alpha equal to .745. The Italian version of the GQ-6 was, as expected, positively correlated with subjective happiness, life satisfaction and social desirability and was negatively associated with loneliness, which supported its construct validity. The Italian version of the GQ-6 also showed a discriminant validity relative to other positive affects and a good criterion validity in differentiating both believers and nonbelievers and high and low envious people.
\end{abstract}

Keywords: gratitude, happiness, life satisfaction, loneliness, social desirability

\section{Introduction}

Recent literature has highlighted the influence of the experience and expression of gratitude on individual emotional, social, and physical wellbeing (Emmons \& McCullough, 2003; Froh et al., 2008; Watkins, Woodward, Stone, \& Kolts, 2003). Indeed, the grateful disposition has been found to be positively associated with many quality of life related measures, such as happiness (Watkins et al., 2003), optimism (Chen, Chen, Kee, \& Tsai, 2009), subjective wellbeing (Emmons \& McCullough, 2003; McCullough, Emmons, \& Tsang, 2002; Thomas \& Watkins, 2003; Watkins et al., 2003; Wood, Froh, \& Geraghty, 2010) and positive affect (Emmons \& McCullough, 2003; McCullough et al., 2002; Thomas \& Watkins, 2003; Watkins et al., 2003). On the contrary, negative associations have been detected between the grateful disposition and depression (Thomas \& Watkins, 2003; Watkins et al., 2003), negative affect (Thomas \& Watkins, 2003), and aggression (Watkins et al., 2003). In addition, dispositional gratitude seems to represent a possible protective factor in healthcare (Jans-Beken, Lataster, Leontjevas, \& Jacobs, 2015) because many of its correlates have a relevant role in cardiovascular disease (Suinn, 2001), hypertension (Shapiro \& Goldstein, 1982) and immune system dysfunction (Graham, Christian, \& Kiecolt-Glaser, 2006).

The Gratitude Questionnaire (GQ-6; McCullough et al., 2002) is one of the most commonly used self-report measures of dispositional gratitude in recent research. The GQ-6 has been reported to be a unidimensional measure with good psychometric properties (McCullough et al., 2002). Indeed, confirmatory factor analyses specifying a one-factor congeneric measurement model typically yield goodness-of-fit indexes that are typically considered to be within acceptable ranges. In addition, Inter-Item Consistency Cronbach's alpha estimates have ranged from .76 to .84 (McCullough et al., 2002). 
Although the GQ-6 has been translated and used in different Western and Asian countries (e.g., Chen et al., 2009; Jans-Beken et al., 2015; Yüksel \& Oğuz Duran, 2012), no measure of gratitude has been validated in the Italian literature to date. Therefore, this paper aims at translating the GQ-6 into Italian and at investigating its validity and reliability in this context for use in both research and clinical practice.

\section{Method}

\subsection{Translation of GQ-6 into Italian}

For the translation of the GQ-6 into Italian, a four-step methodology was used (Sousa \& Rojjanasrirat, 2011):

- Forward translation: Two translators with a good command over English and a linguistics expert each independently translated the original inventory from English to Italian.

- Reconciliation: The translators and the linguist compared the forward versions with the original inventory and reconciled their differences.

- Back translation: A professional translator with a good command over both Italian and English translated the reconciled version from Italian back to English.

- Comparison: As a last step, the original and back-translated versions were reevaluated. The back-translation was compared with the original instrument to determine whether there were any differences between the English and Italian versions in meaning and concept coherence. After the necessary corrections, the instrument assumed its final target language version.

This approach provided concept and language equivalence; therefore, an agreement on the instrument's final translation was achieved.

\subsection{Content validity}

After the translation process was completed, experts assessed the Italian version's content validity. Three psychologists were asked to assess the items' content, meaning, and comprehensibility, using terms proposed as inappropriate; appropriate to some extent - item should be revised; appropriate - minor changes required; and quite appropriate (McKenzie, Wood, Kotecki, Clark, \& Brey, 1999). The assessments appropriate - minor changes required and quite appropriate were accepted as appropriate overall, and content validity ratio (CVR) was calculated accordingly (Lawshe, 1975).

\subsection{Face validity}

To test face validity and comprehensibility of the instrument, GQ-6 was pre-tested through participation by 10 volunteer participants. These volunteers evaluated GQ-6 items for readability, comprehensibility, sentence length, and clarity of meaning, to ready the instrument for implementation. After pre-testing, no changes to the content of the Italian version were required. The final version is shown in Table 1 below. 
Table 1. List of the items of the GQ-6

\begin{tabular}{|c|c|c|}
\hline Item No. & Original Version Statement & Italian Version Statement \\
\hline Item 1 & I have so much in life to be thankful for. & $\begin{array}{l}\text { Ho così tanto nella vita di cui essere } \\
\text { riconoscente. }\end{array}$ \\
\hline Item 2 & $\begin{array}{l}\text { If I had to list everything that I felt } \\
\text { grateful for, it would be a very long list. }\end{array}$ & $\begin{array}{l}\text { Se dovessi elencare tutto ciò per cui ho } \\
\text { provato gratitudine, farei un elenco } \\
\text { molto lungo. }\end{array}$ \\
\hline Item 3 & $\begin{array}{l}\text { When I look at the world, I don't see } \\
\text { much to be grateful for. }\end{array}$ & $\begin{array}{l}\text { Quando guardo il mondo, non vedo } \\
\text { molte cose di cui essere grato. }\end{array}$ \\
\hline Item 4 & I am grateful to a wide variety of people. & $\begin{array}{l}\text { Sono grato a un gran numero di } \\
\text { persone. }\end{array}$ \\
\hline Item 5 & $\begin{array}{l}\text { As I get older I find myself more able to } \\
\text { appreciate the people, events, and } \\
\text { situations that have been part of my life } \\
\text { history. }\end{array}$ & $\begin{array}{l}\text { Con l'avanzare dell'età mi sento più in } \\
\text { grado di apprezzare persone, eventi e } \\
\text { situazioni che hanno fatto parte della } \\
\text { storia della mia vita. }\end{array}$ \\
\hline Item 6 & $\begin{array}{l}\text { Long amounts of time can go by before } \\
\text { I feel grateful to something or someone. }\end{array}$ & $\begin{array}{l}\text { Può passare molto tempo prima che io } \\
\text { mi senta grato verso qualcosa o } \\
\text { qualcuno. }\end{array}$ \\
\hline
\end{tabular}

Note: Items score on a 7-point Likert-type scale ranging from 1 (strongly disagree) to 7 (strongly agree). Items 3 and 6 are reverse scored.

\subsection{Participants}

A convenience sample of 204 participants was recruited (163 women and 41 men) whose mean age was $28.96(S D=10.27)$. A questionnaire was administered which included sociodemographic information and gratitude, loneliness, social desirability, subjective happiness and life satisfaction measures. Participants were guaranteed anonymity. For the present study, 100\% of the respondents filled in the complete questionnaire without missing data. The sample size was considered acceptable because one common rule of thumb is to ensure a person-to-item ratio of $10: 1$.

\subsection{Measures}

\subsubsection{Dispositional gratitude}

The Gratitude Questionnaire (GQ-6; McCullough et al., 2002) is a six-item 7-point Likert-type scale, with alternatives ranging from 1 ("strongly disagree") to 7 ("strongly agree"). A total score is derived from the sum of all items, ranging from 6 to 42, with higher scores reflecting higher levels of gratitude. Items on the GQ-6 assess four facets of gratitude: (1) intensity, which refers to feeling more intensely grateful than would someone less disposed toward gratitude, (2) frequency, which refers to feeling grateful many times each day, (3) span, which refers to the number of life circumstances for which a person feels grateful during a given time, and (4) density, which refers to the number of persons to whom one feels grateful for a single positive outcome.

\subsubsection{Loneliness}

The Three-Item Loneliness Scale, developed by Hughes, Waite, Hawkley and Cacioppo (2004) from the revised UCLA Loneliness Scale, was used to assess loneliness, consisting of feelings of isolation, disconnectedness, and not belonging. The response categories were coded 1 (hardly ever), 2 (some of the time), and 3 (often) on a 3-point scale. Each person's responses to the 
questions are summed, with higher scores indicating greater loneliness. For the purpose of this study, the three items were derived from the Italian version of the revised UCLA Loneliness Scale (Solano \& Coda, 1994). The three-item scale showed a good internal consistency $(\alpha=.844)$.

\subsubsection{Social desirability}

The Italian adaptation (Manganelli Rattazzi, Canova, \& Marcorin, 2000) of the short nine-item version of the Marlowe-Crowne Social Desirability Scale (MC-SDS) was used to measure social desirability. Participants were requested to respond to each item on a 7-point scale. A total score is derived from the sum of all items, ranging from 7 to 63 . Higher scores indicate higher levels of social desirability. Internal consistency was sufficient $(\alpha=.604)$. The relatively low Cronbach's alpha seems to be in agreement with other studies using the Italian short version of the MC-SDS (Maino \& Aceti, 1997; Manganelli Rattazzi et al., 2000).

\subsubsection{Subjective happiness}

The Subjective Happiness Scale (SHS) (Lyubomirsky \& Lepper, 1999) is a widely used four-item scale, measuring global subjective happiness. The scale required participants to use absolute ratings to characterize themselves as happy or unhappy individuals on a 7-point Likert scale, and also asked to what extent they identify themselves with the description of "happy" or "unhappy" individuals. The score was calculated as the mean of items, ranging from 1 to 7. Higher scores mean greater perceived happiness. The Italian version of the scale was used (Duncan \& Grazzani-Gavazzi, 2004) and showed a Cronbach's alpha of .843.

\subsubsection{Life satisfaction}

As a measure of global life satisfaction, a three-item scale was specifically developed and used for the purpose of the study. Subjects had to rate how much they were satisfied with three dimensions respectively, regarding socio-economic status, general health status, and lifestyle and conditions, using a 10-point agreement scale. The score was calculated as the sum of items, ranging from 3 to 30. Higher scores mean better life satisfaction. The scale showed good psychometric properties, with a Cronbach's alpha of .769 and a one-factor solution explaining $68.70 \%$ of the overall variance.

\subsection{Procedure}

A web-based survey was promoted via social media (forums, blogs, social networks) which was aimed at studying the relationship between subjective wellbeing and other related psychological constructs. It was conducted according to online survey design, development, and implementation guidelines suggested by Andrews, Nonnecke, and Preece (2003). An online survey was chosen because of its widespread use for quality of life, health-related and wellbeing research (Vereecken \& Maes, 2006) and its easy access to geographically diverse respondent groups across the national context (Evans \& Mathur, 2005). In addition, the validity and reliability of internet research for subjective wellbeing surveys were demonstrated to be comparable to those of the paper-based versions (Howell, Rodzon, Kurai, \& Sanchez, 2010). 


\subsection{Statistical Analyses}

\subsubsection{Testing assumptions}

Distributional properties of the scale were inspected to examine the normality of the total scores. Skewness and kurtosis values between -2 and +2 were assumed to indicate an acceptable range to prove normal univariate distribution (George \& Mallery, 2010).

\subsubsection{Construct validity}

To test construct validity, the total sample $(n=204)$ was divided into two groups by using the odd-even split method: Group A $(n=102)$ and Group B $(n=102)$. Group A was used for exploratory factor analysis (EFA) to establish the factor structure, and Group B was used for confirmatory factor analysis (CFA) to confirm the GQ-6 factor structures found in Group A.

EFA with a maximum likelihood (ML) was performed to extract underlying common variance among items loaded on their respective factors. In this regard, several researchers and statistical practitioners advocate the use of ML over other methods because of its sensitivity to model misspecification, because less sensitivity to model misspecification can lead to higher type II error rates (Olsson, Foss, Troye, \& Howell, 2000). Each item was included in a specific factor if there was a minimal factor loading of 0.3 , while to determine how many factors should be retained, two main criteria were used (Fabrigar, Wegener, MacCallum, \& Strahan, 1999):

- The Kaiser criterion to select those factors that have an eigenvalue $>1$. Because this criterion could misrepresent the most appropriate number of factors, we also calculated confidence intervals (CIs) for the eigenvalues;

- Parallel analysis, a method based on the generation of random variables, to determine the number of factors to retain. In this procedure, eigenvalues extracted from experimental data (i.e., values forming a standard scree plot) are plotted against those extracted from randomly generated data. Components with eigenvalues exceeding those extracted from the random data are considered for retention. For this study, 100 randomly generated data sets equal in size to the experimental data were constructed.

To assess the sampling adequacy, a Kaiser-Meyer-Olkin (KMO) measure was conducted. A $\mathrm{KMO}$ is considered good when the outcome is between $0.7-0.8$, and excellent when between 0.8 - 0.9 (Hutcheson \& Sofroniou, 1999). Anti-image correlations of $>0.5$ were regarded acceptable (Field, 2013).

In relation to CFA on the second sub-sample, different components of fit were evaluated (Hu \& Bentler, 1995). Indeed, it is generally recommended that multiple measures be considered to highlight different aspects of fit (Tanaka, 1993). The $\chi^{2}$ ratio $\left(\chi^{2} /\right.$ degrees of freedom $\left.[d f]\right)$ was used to evaluate stand-alone models. This index tends to be less sensitive to sample size, and values less than 3 (or in some instances 5) are often taken to indicate acceptable models (Kline, 2010). We also evaluated model fit using the root mean square error of approximation (RMSEA), standardized root mean square residual (SRMR), Confirmatory Fit Index (CFI; Bentler, 1990), Tucker-Lewis Index (TLI), Akaike Information Criterion (AIC; Akaike, 1987), and Bayesian Information Criterion (BIC; Schwarz, 1978). Smaller $\chi^{2}$, AIC, and BIC values correspond to better fitting models (Schumacker \& Lomax, 2010). As Hu and Bentler (1999) indicated, RMSEA values up to .05 indicate good fit, between .06 and .08 indicate adequate fit, and >.10 indicate poor fit; SRMR values below .08 are indicative of a good fit; CFI and TLI values greater than .90 are generally indicative of acceptable model fit. 


\subsubsection{Convergent/divergent validity}

Evidence for convergent and divergent construct validity was evaluated by examining Pearson's correlations between the GQ-6 and the other measures. Based on previous studies on GQ-6, it was hypothesized that it should be positively correlated with life satisfaction and subjective happiness, as well as with social desirability tendencies (McCullough et al., 2002). On the contrary, it was expected to be negatively associated with loneliness because people who report greater levels of gratitude also tend to show less subjective feelings of loneliness (Breen, Kashdan, Lenser, \& Fincham, 2010; Caputo, 2015).

\subsubsection{Discriminant validity}

We proceeded to distinguish our measure of the grateful disposition from related but distinct constructs concerning positive emotions, such as life satisfaction and subjective happiness. For each of these tests of discriminant validity, we estimated a one-factor solution specifying a single latent construct underlying the items on the GQ- 6 and each of the other respective scales. Second, we estimated a two-factor solution specifying that the items on the GQ-6 and each of the other respective scales loaded on distinct but correlated latent variables. If the addition of a second latent variable to account for the covariances among both sets of items led to an improvement in model fit (i.e., if the two-factor model was superior to the one-factor model), we could conclude that both constructs are necessary for describing the two sets of items, and thus, that the two constructs are reasonably distinctive.

\subsubsection{Criterion validity}

Criterion validity was evaluated by using an independent-samples $t$ test to compare different groups based on two concurrent measures: religiousness and envy (McCullough et al., 2002). With regard to religiousness, the believers group was expected to be higher in GQ-6 score than the non-believers one because grateful people are more likely to cite religious or spiritual causes as responsible for the positive life events that they experience. With regard to envy, a single item derived from the social desirability scale was used which stated, "Sometimes I have been envious of others' fortune." The participants group that reported envious feelings above the median was expected to score lower on GQ-6 compared to the group below it.

\subsubsection{Reliability}

The final version of the GQ-6 was examined to assess the reliability of test scores. Internal consistency is measured by Cronbach's alpha correlation coefficient. Internal consistency is considered excellent when Cronbach's alpha is greater than .9 , good when it ranges between 8 and .9 , acceptable between .7 and .8 , questionable between .6 and .7 , and poor when it is lower than .6.

\subsubsection{Supplementary analyses}

The total score of the GQ-6 was used to test potential differences by gender (independentsamples $t$ test) and age. Given the relatively low mean age of our sample, we performed both a correlation analysis (Pearson's r) and independent-samples $t$ test comparing younger (aged 1829 ) and older (aged $>29$ ) adults.

\section{Results}

In Table 2 below, socio-demographic variables of our sample are reported. 
Table 2. Socio-demographic variables of the sample $(\mathrm{N}=204)$

\begin{tabular}{lcc}
\hline Categorical variables & $n$ & $\%$ \\
\hline Gender & 41 & 20.10 \\
$\quad$ Male & 163 & 79.90 \\
$\quad$ Female & & \\
Marital/Relationship status & 64 & 31.37 \\
$\quad$ Married-Cohabitant & 60 & 29.41 \\
$\quad$ In a relationship & 80 & 39.22 \\
$\quad$ Single & & \\
Employment status & 85 & 41.67 \\
$\quad$ Employed & 33 & 16.17 \\
$\quad$ Unemployed & 86 & 42.16 \\
$\quad$ Others & & \\
Italian territorial area & 94 & 46.10 \\
$\quad$ North & 60 & 29.40 \\
$\quad$ Centre & 50 & 24.50 \\
$\quad$ South and Islands & & \\
Religiousness & 125 & 61.27 \\
$\quad$ Believers & 79 & 38.73 \\
$\quad$ Non believers & $\boldsymbol{M}$ & 10.27 \\
\hline Continuous variables & 28.96 & 3.49 \\
\hline Age & 13.44 & \\
Education (years) & & \\
\hline Other inlude & & \\
\hline
\end{tabular}

* Others include homemakers, students or retired.

Table 3 below presents descriptive statistics and indexes of skewness and kurtosis for each item of the scale. No missing data were present. Based on these results, it could be concluded that normality assumptions were tenable because values for skewness and kurtosis between -2 and +2 are considered acceptable in order to prove normal univariate distribution (George \& Mallery, 2010).

Table 3. Distributional indexes of the items

\begin{tabular}{lcccccc}
\hline Item No. & Range & $\boldsymbol{M}$ & $\boldsymbol{S E}$ & $\boldsymbol{S D}$ & Skewness & Kurtosis \\
\hline Item 1 & $1-7$ & 4.72 & .13 & 1.80 & -.64 & -.70 \\
Item 2 & $1-7$ & 4.42 & .12 & 1.68 & -.17 & -.93 \\
Item 3 & $1-7$ & 4.12 & .13 & 1.93 & .05 & -1.30 \\
Item 4 & $1-7$ & 3.65 & .12 & 1.74 & .10 & -1.08 \\
Item 5 & $1-7$ & 4.78 & .13 & 1.84 & -.54 & -.76 \\
Item 6 & $1-7$ & 3.95 & .13 & 1.92 & -.05 & -1.28 \\
\hline
\end{tabular}

Note: $S D=$ standard deviation; $S E=$ standard error.

An EFA was used to test the dimensionality of the GQ-6 from a randomly chosen half of the sample $(n=102)$, and the remaining responses were saved for a CFA. In the initial EFA, one factor with an eigenvalue greater than 1.0 was extracted, which accounted for $46.16 \%$ of the variance of the original items. Parallel analysis confirmed that one factor should be retained because only the first eigenvalue (equal to 2.60) from our actual data set exceeded the 95th percentile of 
eigenvalues derived from random data sets $(C I=1.89,3.31)$. Therefore, the results of this EFA were not rotated. The KMO of 0.76 verified the sampling adequacy for the EFA. Anti-image correlation values for individual items were all $>0.70$, which is well above the acceptable limit of 0.50. As shown in Table 4 below, overall factor loadings were satisfactory (from -.34 to .89), while communalities ranged from .40 to .82 . Item 6 had the lowest communality, which consequently led to the low level of its factor loading, despite it being above the threshold of 30 .

Table 4. Loading for exploratory factor analysis

\begin{tabular}{lcc}
\hline Item No. & Loadings & Communalities \\
\hline Item 1 & .89 & .82 \\
Item 2 & .88 & .78 \\
Item 3 & -.54 & .44 \\
Item 4 & .52 & .47 \\
Item 5 & .60 & .62 \\
Item 6 & -.34 & .40 \\
\hline
\end{tabular}

Note: Extraction method-maximum likelihood

To test the hypothetical structure of the scale extracted from EFA, a CFA with ML estimation was used on the second half of the sample $(n=102)$. Because of the low factor loading of item 6 , we performed two CFAs, considering also a five-item solution, which, according to previous studies (Chen et al., 2009; Froh et al., 2011; Yüksel \& Oğuz Duran, 2012), seems to fit data better. The CFA confirmed the one-factor solution of the scale and better fit indexes were revealed for the item 6 one, as shown in Table 5 below.

Table 5. Goodness-of-fit Indexes

\begin{tabular}{lccccccccc}
\hline $\begin{array}{l}\text { Factor } \\
\text { solution }\end{array}$ & $\chi^{2}$ & $d f$ & $\chi^{2 / d f}$ & $\begin{array}{c}\text { RMSEA } \\
{[90 \% \text { CI }]}\end{array}$ & AIC & BIC & CFI & TLI & SRMR \\
\hline Six items & 11.398 & 9 & 1.27 & 0.051 & $2,366.682$ & $2,413.754$ & 0.980 & 0.967 & 0.049 \\
& & & & {$[0.000$,} & & & & & \\
& & & & $0.130]$ & & & & & \\
Five items & 7.950 & 5 & 1.59 & 0.076 & $1,955.054$ & $1,994.281$ & 0.974 & 0.948 & 0.043 \\
& & & & {$[0.000$,} & & & & & \\
& & & & & & & & \\
\end{tabular}

Note: RMSEA = root mean square error of approximation; $\mathrm{CI}=$ confidence interval; AIC $=$ Akaike Information Criterion; BIC = Bayesian Information Criterion; CFI = Comparative Fit Index; TLI = TuckerLewis Index; SRMR = standardized root mean square residual.

The total score of the GQ-6 was then used for subsequent validity and reliability analyses on the total sample $(n=204)$. Consistenly with the theoretical framework, positive correlations with subjective happiness, life satisfaction and social desirability were detected; on the contrary, GQ6 was negatively associated with loneliness (Table 6 below). 
Table 6. Correlations between GQ-6 total score and other measures

\begin{tabular}{lcc}
\hline & Pearson's correlation & $p$ value \\
\hline Subjective Happiness & .569 & $<.001$ \\
Life Satisfaction & .448 & $<.001$ \\
Loneliness & -.411 & $<.001$ \\
Social Desirability & .291 & $<.001$ \\
\hline
\end{tabular}

As expected, discriminant validity analyses showed better fit indexes of the two-factor solutions combining the gratitude items with both the life satisfaction and subjective happiness ones respectively (Table 7 below).

Table 7. Goodness-of-fit indexes for discriminant validity

\begin{tabular}{|c|c|c|c|c|c|c|c|c|c|}
\hline Model & $\chi^{2}$ & $d f$ & $\chi^{2} / d f$ & $\begin{array}{l}\text { RMSEA } \\
{[90 \% \text { CI }]}\end{array}$ & AIC & BIC & CFI & TLI & SRMR \\
\hline \multicolumn{10}{|c|}{ Life Satisfaction } \\
\hline $\begin{array}{l}\text { One-factor } \\
\text { solution }\end{array}$ & 156.838 & 27 & 5.81 & $\begin{array}{c}0.154 \\
{[0.131} \\
0.178]\end{array}$ & $7,108.855$ & $7,198.311$ & 0.765 & 0.687 & 0.083 \\
\hline $\begin{array}{l}\text { Two-factor } \\
\text { solution }\end{array}$ & 45.425 & 26 & 1.75 & $\begin{array}{r}0.061 \\
{[0.029} \\
0.089]\end{array}$ & $6,999.442$ & $7,092.211$ & 0.965 & 0.951 & 0.046 \\
\hline \multicolumn{10}{|c|}{ Subjective Happiness } \\
\hline $\begin{array}{l}\text { One-factor } \\
\text { solution }\end{array}$ & 200.598 & 35 & 5.73 & $\begin{array}{c}0.153 \\
{[0.133} \\
0.174]\end{array}$ & $7,559.086$ & $7,658.483$ & 0.800 & 0.743 & 0.082 \\
\hline $\begin{array}{l}\text { Two-factor } \\
\text { solution }\end{array}$ & 81.071 & 34 & 2.38 & $\begin{array}{c}0.083 \\
{[0.060} \\
0.106]\end{array}$ & $7,441.559$ & $7,544.269$ & 0.943 & 0.925 & 0.055 \\
\hline
\end{tabular}

We can thus conclude that gratitude is a reasonably distinctive theoretical construct from the other ones, despite it being highly correlated with both the life satisfaction $(r=.54, p<.001)$ and subjective happiness $(r=.70, p<.001)$ latent factors.

Then criterion-related validity was also confirmed. The believers group reported higher gratitude $(M=26.60 ; S D=6.64)$ than the non-believers one $(M=23.84 ; S D=7.84) ; \mathrm{t}(201)=2.69, p$ $=.008$. In addition, the participants who reported fewer envious feelings than their counterparts (based on the median value of the overall sample) scored higher in gratitude $(\mathrm{M}=26.76, S D=$ 7.09) compared to the participants who reported greater envy $(M=22.74, \mathrm{SD}=6.86) ; \mathrm{t}(140)=3.43$, $p=.001$.

In regard to internal consistency, Cronbach's alpha for the scale was acceptable, with a value of .745. The entire scale presented a mean of 25.49 and a standard deviation of 7.33 units. The inter-item correlation was on average .335 and the item-total correlation ranged from .404 to .698 , with the exception of item 6, which showed a lower value (.288), and, if deleted, led to a slight alpha improvement up to .763 . However, it was not eliminated because of the results from the previous CFA.

The independent-samples $t$ test did not show any difference in GQ-6 scores by gender $(M=$ 24.93; $S D=6.92$ for males and $M=25.67 ; S D=7.33$ for females); $\mathrm{t}(201)=.558, \mathrm{p}=.557$. Despite a 
positive correlation with age being found $(r=.146, \mathrm{p}<.05)$, no statistically significant difference was detected between younger (18-29 aged, $M=25.02 ; S D=7.51$ ) and older ( $>29$ aged, $M=26.27$; $S D=6.79)$ adults; $\mathrm{t}(201)=1.21, p=.228$.

\section{Discussion}

The purpose of the present study was to translate the GQ-6 for use with the Italian population. Overall, this study replicated the main findings obtained in previous research with regard to the psychometric properties of the scale. Our results confirm a one-factor solution explaining $46.16 \%$ of the variance of the original items and an acceptable Cronbach's alpha estimate equal to .745. As revealed in previous studies (Chen et al., 2009; Froh et al., 2011; Yüksel \& Oğuz Duran, 2012), item 6 showed a relatively low factor loading compared with other GQ-6 items. In this regard, Chen et al. (2009) explained the misfit of item 6 as due to the lack of diverse life experiences in their sample; while Froh et al. (2011) reported its inappropriateness for young people, since this item is too abstract and difficult for this group to understand. However, the CFA conducted on the factor solution including only the first five items indicated worse fit, therefore the original six-item version was retained. With regard to convergent measures, our results confirm high correlations with life satisfaction, subjective happiness and social desirability consistently with the theoretical framework (McCullough et al., 2002). Indeed, the appreciation for the good things in one's life may lead grateful people to avoid taking benefits for granted and help sustain their happiness and life satisfaction over time (McCullough et al., 2002). Instead, social desirability may lead to report pro-social and altruistic dispositions (such as gratitude) which are culturally agreeable (Lyubomirsky, Sheldon, \& Schkade, 2005; Wood, Froh, \& Geraghty, 2010). Discriminant validity analyses show that grateful disposition is a reasonably distinctive theoretical construct from other positive affects, i.e., life satisfaction and subjective happiness. Instead, a negative correlation has been found with loneliness as a negative emotion (Breen et al., 2010; Caputo, 2015) consistently with the conception of gratitude as "indispensable in the life of one individual who will face isolation and loneliness if the capacity to feel grateful is impaired" (Emmons \& McCullough, 2004, p. 2010). Then, criterion validity with regard to concurrent measures showed that GQ-6 is able to discriminate between the believers and non-believers groups, as well as between more and less envious people. Indeed, gratitude has been demonstrated to be associated with higher spiritual transcendence (Diessner \& Lewis, 2007), religiousness and spirituality (McCullough et al., 2002). Those who regularly attend religious services and engage in religious activities such as prayer and the reading of religious material are more likely to score high on the GQ-6. More grateful people also tend to have higher scores on measures of spirituality that tap a belief in the interconnectedness of all life and a commitment to and responsibility to others (McCullough et al., 2002). Besides, they are less envious of wealthy persons because they are more prosocial and tend to share their possessions with others relative to less grateful persons (McCullough et al., 2002). No gender differences in gratitude were detected, despite previous work which suggests that women might possess an advantage over men in experiencing and benefiting from gratitude (Kashdan, Mishra, Breen, \& Froh, 2009; Schwartz \& Rubel, 2005; Timmers, Fischer, \& Manstead, 1998). Previous research revealed that levels of gratitude vary with age (McAdams \& Bauer, 2004), in detail, older adults may be more prone to viewing gratitude as a positive, rewarding, essential experience compared with younger adults (Kashdan et al., 2009). In this regard, our results show a modest correlation with age, which disappears when comparing younger (aged up to 29) and older (aged more than 29) adult groups, though it could depend on our relatively young sample, which does not have enough age-related variability. Based on the summary of means and standard deviations for GQ-6 scores 
across several studies, our Italian sample reported a lower mean score. This could depend on the nature of the online survey because positive emotions scores tend to be lower in online questionnaires compared with face-to-face interviews (Peck, Olsen, \& Devore, 2011), mostly due to the reduced socially desirable responding in computer testing formats (Dwight \& Feigelson, 2000). Further surveys could be thus carried out in face-to-face settings in order to understand whether the lower gratitude in our sample is due to the specific testing format or is related to the Italian cultural context. In conclusion, the results of the current study indicated that the GQ-6 possessed a good reliability and construct, convergent/divergent, discriminant and criterion validity, thus replicating and extending previous studies. Therefore, GQ-6 can be used to assess the grateful disposition in an Italian speaking sample and may be potentially useful in both research and clinical practice in the future.

\section{Author}

Andrea Caputo

Sapienza University of Rome

andrea.caputo@uniroma1.it

\section{Publishing Timeline}

Received 22 December 2015

Accepted 25 June 2016

Published 14 September 2016

\section{References}

Akaike, H. (1987). Factor analysis and the AIC. Psychometrika, 52, 317-332. http://dx.doi.org/10.1007/BF02294359

Andrews, D., Nonnecke, B., \& Preece, J. (2003). Electronic survey methodology: A case study in reaching hard-to-involve internet users. International Journal of Human-Computer Interaction, 16(2), 2185-2210. http://dx.doi.org/10.1207/S15327590IJHC1602 04

Bentler, P. M. (1990). Comparative fit indices in structural models. Psychological Bulletin, 107, 238-246. http://dx.doi.org/10.1037/0033-2909.107.2.238

Breen, W. E., Kashdan, T. B., Lenser, M. L., \& Fincham, G. D. (2010). Gratitude and forgiveness: Convergence and divergence on self-report and informant ratings. Personality and Individual Differences, 49, 932-937. http://dx.doi.org/10.1016/j.paid.2010.07.033

Caputo, A. (2015). The relationship between gratitude and loneliness: The potential benefits of gratitude for promoting social bonds. Europe's Journal of Psychology, 11(2), 323-334 http://dx.doi.org/10.5964/ejop.v11i2.826

Chen, L. H., Chen, M. Y., Kee, Y. H., \& Tsai, Y. M. (2009). Validation of the Gratitude Questionnaire (GQ6) in Taiwanese undergraduate students. Journal of Happiness Studies, 10(6), 655-664. http://dx.doi.org/10.1007/s10902-008-9112-7

Diessner, R., \& Lewis, G. (2007). Further validation of the Gratitude, Resentment, and Appreciation Test (GRAT). Journal of Social Psychology, 147(4), 445-447. http://dx.doi.org/10.3200/SOCP.147.4.445-448

Duncan, E., \& Grazzani-Gavazzi, I. (2004). Positive emotional experiences in Scottish and Italian young adults: A diary study. Journal of Happiness Studies, 5, 359-384. http://dx.doi.org/10.1007/s10902-0040666-8

Dwight, S. A., \& Feigelson, M. E. (2000). A quantitative review of the effect of computerized testing on the measurement of social desirability. Educational and Psychological Measurement, 60, 340-360. http://dx.doi.org/10.1177/00131640021970583

Emmons, R. A., \& McCullough, M. E. (2003). Counting blessings versus burdens: An experimental investigation of gratitude and subjective well-being in daily life. Journal of Personality $\mathcal{E}$ Social Psychology, 84(2), 377-389. http://dx.doi.org/10.1037/0022-3514.84.2.377 
Emmons, R. A., \& McCullough, M. E. (2004). The psychology of gratitude. New York, NY: Oxford University Press. http://dx.doi.org/10.1093/acprof:oso/9780195150100.001.0001

Evans, J., \& Mathur, A. (2005). The value of on-line surveys. Internet Research, 15(2), 2195-219. http://dx.doi.org/10.1108/10662240510590360

Fabrigar, L. R., Wegener, D. T., MacCallum, R. C., \& Strahan, E. J. (1999). Evaluating the use of exploratory factor analysis in psychological research. Psychological Methods, 4, 272-299. http://dx.doi.org/10.1037/1082-989X.4.3.272

Field, A. (2013). Discovering statistics using SPSS. London: Sage.

Froh, J., Fan, J., Emmons, R. A., Bono, G., Huebner, E. S., \& Watkins, P. (2011). Measuring gratitude in youth: Assessing the psychometric properties of adult gratitude scales in children and adolescents. Psychological Assessment, 23(2), 311-324. http://dx.doi.org/10.1037/a0021590

George, D., \& Mallery, M. (2010). SPSS for Windows step by step: A simple guide and reference, 17.0 update (10th ed.). Boston: Pearson.

Graham, J. E., Christian, L. M., \& Kiecolt-Glaser, J. K. (2006). Stress, age, and immune function: Toward a lifespan approach. Journal of Behavioral Medicine, 29(4), 389-400. http://dx.doi.org/10.1007/s10865-0069057-4

Howell, R. T., Rodzon, K. S., Kurai, M., \& Sanchez, A. H. (2010). A validation of well-being and happiness surveys for administration via the internet. Behavior Research Methods, 42(3), 3775-3784. http://dx.doi.org/10.3758/BRM.42.3.775

Hu, L. T., \& Bentler, P. M. (1995). Evaluating model fit. In R. H. Hoyle (Ed.), Structural equation modeling: Concepts, issues, and applications (pp. 76-99). Thousand Oaks, CA: Sage.

Hu, L. T., \& Bentler, P. M. (1999). Cutoff criteria for fit indexes in covariance structure analysis: Conventional criteria versus new alternatives. Structural Equation Modeling, 6, 1-55. http://dx.doi.org/10.1080/10705519909540118

Hughes, M. E., Waite, L. J., Hawkley, L. C., \& Cacioppo, J. T. (2004). A short scale for measuring loneliness in large surveys: Results from two population-based studies. Research on Aging, 26, 655672. http://dx.doi.org/10.1177/0164027504268574

Hutcheson, G. D., \& Sofroniou, N. (1999). The multivariate social scientist: Introductory statistics using generalized linear models. Thousand Oaks, CA: Sage. http://dx.doi.org/10.4135/9780857028075

Jans-Beken, L., Lataster, J., Leontjevas, R., \& Jacobs, N. (2015). Measuring gratitude: A comparative validation of the Dutch Gratitude Questionnaire (GQ6) and Short Gratitude, Resentment, and Appreciation Test (SGRAT). Psychologica Belgica, 55(1), 19-31. http://dx.doi.org/10.5334/pb.bd

Kashdan, T. B., Mishra, A., Breen, W. E., \& Froh, J. J. (2009). Gender differences in gratitude: Examining appraisals, narratives, the willingness to express emotions, and changes in psychological needs. Journal of Personality, 77(3), 691-730.

Kline, R. B. (2010). Principles and practice of structural equation modeling (3rd ed.). New York, NY: Guilford Press.

Lawshe, C. H. (1975). A quantitative approach to content validity. Personnel Psychology, 28, 563-575. http://dx.doi.org/10.1111/j.1744-6570.1975.tb01393.x

Lyubomirsky, S., \& Lepper, H. S. (1999). A measure of subjective happiness: Preliminary reliability and construct validation. Social Indicators Research, 46, 137-155. http://dx.doi.org/10.1023/A:1006824100041

Lyubomirsky, S., Sheldon, K. M., \& Schkade, D. (2005). Pursuing happiness: The architecture of sustainable change. Review of General Psychology, 9, 111-131. http://dx.doi.org/10.1037/10892680.9.2.111

Maino, E., \& Aceti, G. (1997). Contributo all'adattamento italiano della Marlowe-Crowne Social Desirability Scale [Contribution to the Italian adaptation of the Marlowe-Crowne Social Desirability Scale]. TPM - Testing, Psychometrics, Methodology in Applied Psychology, 4(2), 281-93.

Manganelli Rattazzi, A. M., Canova, L., \& Marcorin, R. (2000). La desiderabilità sociale: Un'analisi di forme brevi della scala di Marlowe e Crowne [Social desirability: An analysis of short forms of the Marlowe-Crowne Social Desirability Scale]. TPM - Testing, Psychometrics, Methodology in Applied Psychology, 7(1), 15-17. 
McAdams, D. P., \& Bauer, J. J. (2004). Gratitude in modern life: Its manifestations and development. In R. A. Emmons \& M. McCullough (Eds.), The psychology of gratitude (pp. 81-99). New York: Oxford University Press. http://dx.doi.org/10.1093/acprof:oso/9780195150100.003.0005

McCullough, M. E., Emmons, R. A., \& Tsang, J. A. (2002). The grateful disposition: A conceptual and empirical topography. Journal of Personality \& Social Psychology 82(1), 112-127. http://dx.doi.org/10.1037//0022-3514.82.1.112

McKenzie, J. F., Wood, M. L., Kotecki, J. E., Clark, J. K., \& Brey, R. A. (1999). Establishing content validity: Using qualitative and quantitative steps. American Journal of Health Behavior, 23, 311-318. http://dx.doi.org/10.5993/AJHB.23.4.9

Olsson, U. H., Foss, T., Troye, S. V., \& Howell, R. D. (2000). The performance of ML, GLS, and WLS estimation in structural equation modeling under conditions of misspecification and nonnormality. Structural Equation Modeling, 7, 557-595. http://dx.doi.org/10.1207/S15328007SEM0704 3

Peck, R., Olsen, C., \& Devore, J. (2011). Introduction to statistics and data analysis (4th ed.). Boston, MA: Brooks/Cole.

Schumacker, R. E., \& Lomax, R. G. (2010). A beginner's guide to structural equation modeling. Mahwah, NJ: Lawrence Erlbaum.

Schwartz, S. H., \& Rubel, T. (2005). Sex differences in value priorities: Cross-cultural and multimethod studies. Journal of Personality and Social Psychology, 89(6), 1010-28. http://dx.doi.org/10.1037/00223514.89.6.1010

Schwarz, G. (1978). Estimating the dimension of a model. Annals of Statistics, 6, 461-464. http://dx.doi.org/10.1214/aos/1176344136

Shapiro, D., \& Goldstein, I. B. (1982). Biobehavioral perspectives on hypertension. Journal of Consulting and Clinical Psychology, 50(6), 841-858. http://dx.doi.org/10.1037/0022-006X.50.6.841

Solano, L., \& Coda, R. (1994). Relazioni, emozioni, salute: Introduzione alla psicoimmunologia [Relationships, emotions and health: Introduction to psychoimmunology]. Padua, Italy: Piccin.

Sousa, V., \& Rojjanasrirat, W. (2010). Translation, adaptation and validation of instruments or scales for use in cross-cultural health care research: A clear and user friendly guideline. Journal of Evaluation in Clinical Practice, 17(2), 268-274. http://dx.doi.org/10.1111/j.1365-2753.2010.01434.x

Suinn, R. M. (2001). The Terrible Twos: Anger and Anxiety. American Psychologist, 56(1), 27-36. http://dx.doi.org/10.1037/0003-066X.56.1.27

Tanaka, J. S. (1993). Multifaceted conceptions of fit in structural equation models. In K. A. Bollen \& J. S. Long (Eds.), Testing structural equation models (pp. 10-39). Newbury Park, CA: Sage.

Thomas, M., \& Watkins, P. (2003). Measuring the grateful trait: Development of revised GRAT. Paper presented at the Annual Convention of the Western Psychological Association, Vancouver, British Columbia, Canada.

Timmers, M., Fischer, A. H., \& Manstead, A. S. R. (1998). Gender differences in motives for regulating emotions. Personality and Social Psychology Bulletin, 24(9), 974-985.

http://dx.doi.org/10.1177/0146167298249005

Vereecken, C. A., \& Maes, L. (2006). Comparison of a computer administered and paper-and penciladministered questionnaire on health and lifestyle behaviors. The Journal of Adolescent Health, 38(4), 4426-432. http://dx.doi.org/10.1016/j.jadohealth.2004.10.010

Watkins, P., Woodward, K., Stone, T., \& Kolts, R. (2003). Gratitude and happiness: Development of a measure of gratitude and relationships with subjective well-being. Social Behavior and Personality, 31(5), 431-451. http://dx.doi.org/10.2224/sbp.2003.31.5.431

Wood, A. M., Froh, J. J., \& Geraghty, A. W. A. (2010). Gratitude and well-being: A review and theoretical integration. Clinical Psychology Review, 30, 890-905. http://dx.doi.org/10.1016/j.cpr.2010.03.005

Yüksel, A., \& Oğuz Duran, N. (2012). Turkish adaptation of gratitude questionnaire. Eurasian Journal of Educational Research, 46, 199-216. 